\title{
Erratum to: Study of the kinetic and energetic reaction properties of multilayered aluminum-nickel nanofoils
}

\author{
Georgios D. Theodossiadis ${ }^{1} \cdot$ Michael F. Zaeh ${ }^{1}$
}

Published online: 12 June 2017

(C) German Academic Society for Production Engineering (WGP) 2017

\section{Erratum to: Prod. Eng. Res. Devel. (2017) 11:245-} 253 DOI 10.1007/s11740-017-0733-8

The original version of this article unfortunately contained a mistake.

The legend of Fig. 7 was incorrect. The correct legend and figure is given here.

\section{Reference}

33. Jayaraman S, Knio OM, Mann AB, Weihs TP (1999) Numerical predictions of oscillatory combustion in reactive multilayers. J Appl Phys 86(2):800-809

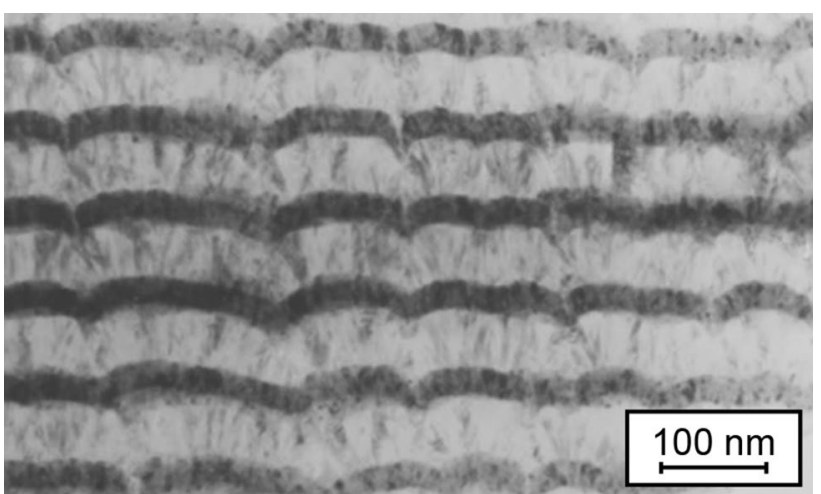

Fig. 7 TEM image of a cross section of a reactive Al-Ni nanofoil sample with $50 \mathrm{~nm}$ thick bilayers, fabricated by magnetron sputtering; constituents of the layer structure: aluminum (bright) and nickel (dark) (Jayaraman et al. [33])
The online version of the original article can be found under doi:10.1007/s11740-017-0733-8.

Georgios D. Theodossiadis

info@iwb.mw.tum.de

1 Institute for Machine Tools and Industrial Management (iwb), Technical University of Munich (TUM), Boltzmannstr. 15, 85748 Garching, Germany 